\title{
Attenuated Influenza Virions Expressing the SARS-CoV-2 Receptor-Binding Domain Induce Neutralizing Antibodies in Mice
}

\author{
Andrea N. Loes ${ }^{1,2}$, Lauren E. Gentles ${ }^{1,3}{ }^{\circledR}$, Allison J. Greaney ${ }^{1,4,5}$, Katharine H. D. Crawford ${ }^{1,4,5}$ \\ and Jesse D. Bloom 1,2,3,4,*(D) \\ 1 Division of Basic Sciences and Computational Biology Program, Fred Hutchinson Cancer Research Center, \\ Seattle, WA 98109, USA; aloes@fredhutch.org (A.N.L.); lgentles@uw.edu (L.E.G.); agreaney@uw.edu (A.J.G.); \\ kdusenbu@fredhutch.org (K.H.D.C.) \\ 2 Howard Hughes Medical Institute, Seattle, WA 98103, USA \\ 3 Department of Microbiology, University of Washington, Seattle, WA 98195-7735, USA \\ 4 Department of Genome Sciences, University of Washington, Seattle, WA 98195, USA \\ 5 Medical Scientist Training Program, University of Washington, Seattle, WA 98195, USA \\ * Correspondence: jbloom@fredhutch.org
}

Received: 13 August 2020; Accepted: 3 September 2020; Published: 5 September 2020

check for updates

\begin{abstract}
An effective vaccine is essential for controlling the spread of the SARS-CoV-2 virus. Here, we describe an influenza virus-based vaccine for SARS-CoV-2. We incorporated a membrane-anchored form of the SARS-CoV-2 spike receptor binding domain (RBD) in place of the neuraminidase (NA) coding sequence in an influenza virus also possessing a mutation that reduces the affinity of hemagglutinin for its sialic acid receptor. The resulting $\triangle \mathrm{NA}(\mathrm{RBD})$-Flu virus can be generated by reverse genetics and grown to high titers in cell culture. A single-dose intranasal inoculation of mice with $\triangle \mathrm{NA}(\mathrm{RBD})$-Flu elicits serum neutralizing antibody titers against SAR-CoV-2 comparable to those observed in humans following natural infection ( 1:200). Furthermore, $\triangle$ NA(RBD)-Flu itself causes no apparent disease in mice. It might be possible to produce a vaccine similar to $\triangle N A(R B D)$-Flu at scale by leveraging existing platforms for the production of influenza vaccines.
\end{abstract}

Keywords: SARS-CoV-2; influenza; intranasal; live attenuated vaccine; spike; RBD

\section{Introduction}

The rapid spread and severity of disease caused by the SAR-CoV-2 virus highlights the need for effective control measures [1-3]. A safe, effective, and scalable vaccine is the most promising way to limit the public health impact of SARS-CoV-2.

The influenza virus is a promising platform for vaccine development. Attenuated influenza viruses are already used as vaccines against influenza itself [4-7]. In addition, well-established influenza reverse genetics systems make it easy to incorporate foreign genes into the viral genome [8-12]. In preclinical animal models, influenza virions expressing foreign antigens induce antibodies against the causative agents of a variety of diseases, including the West Nile virus, Bacillus anthracis, botulinum neurotoxin, and HIV [13-16]. Intranasal infection with influenza viruses induces mucosal immune responses not only within the respiratory tract, but also in mucosal surfaces distal from the site of immunization [15], which may prove important for SARS-CoV-2 [17]. Finally, there is already existing infrastructure for the large-scale production of influenza virions for use in vaccines.

The receptor binding domain (RBD) of the spike glycoprotein is a key antigen candidate for SARS-CoV-2 vaccines [18-23]. Many of the most potent neutralizing antibodies against SARS-CoV-2 
target the RBD [19,24-27]. Additionally, RBD is small in size ( 200 aa), folds autonomously, and is therefore an attractive candidate for protein subunit-based approaches to SARS-CoV-2 vaccinations [19].

Here, we have incorporated a membrane-anchored form of the SARS-CoV-2 spike RBD into the genome of an attenuated influenza A virus. Cells infected with the resulting virus express high levels of RBD on their surface. The inoculation of mice with the virus induces substantial titers of neutralizing antibodies ( 1:200) without causing disease. This influenza virus-based vaccine platform could be useful for combating SARS-CoV-2.

\section{Materials and Methods}

\subsection{Plasmids}

The $\triangle \mathrm{NA}(\mathrm{RBD})$ construct, described in Figure $1 \mathrm{~A}$ and the first results subsection below, used the protein sequence for the receptor binding domain (RBD) of spike from SARS-CoV-2 (isolate Wuhan-Hu-1, Genbank accession number MN908947, residues 331-531). The nucleotide sequence was codon-optimized as previously described [28]. To facilitate the surface expression of the RBD, the murine immunoglobulin $\mathrm{H}$ chain $\mathrm{V}$-region leader sequence was added to the $\mathrm{N}$-terminus. The transmembrane region and cytoplasmic domain of murine B7.1 (CD80) was added to the C-terminus to tether this protein to the cell membrane [29]. To incorporate the sequence for this membrane-anchored RBD into an influenza viral RNA (vRNA), its coding sequence was flanked by the coding and noncoding regions of the packaging signal from the A/WSN/33 influenza NA segment (113 and $126 \mathrm{bp}$ at the $3^{\prime}$ and $5^{\prime}$ ends of the vRNA, respectively) [30,31]. Several mutations were introduced into the $3^{\prime}$ and $5^{\prime}$ packaging signals, including the ablation of ATG start codons in the $3^{\prime}$ vRNA, the ablation of a putative cryptic bacterial translation initiation site, and the introduction of cloning restriction sites between the $3^{\prime}$ and $5^{\prime}$ packaging signals and coding sequences. This construct was cloned into a $\mathrm{pHH}$ vector and expressed via the Pol I promotor [9] to generate the viral stock used for murine infections. Subsequent reverse genetics experiments were performed with this gene cloned into the pHW2000 backbone [32] (pHW_NAflank_RBD_B7-1). A Genbank file for pHW_NAflank_RBD_B7-1 is provided in (File S1).

The $\triangle N A(G F P)$ segment, containing green fluorescent protein (GFP) in place of neuraminidase (NA), was based on the FLU-NA-GFP described in Rimmelzwaan and others [31], except that the NA sequences come from $\mathrm{A} / \mathrm{WSN} / 33$ rather than $\mathrm{A} / \mathrm{PR} / 8 / 34$. GFP was similarly flanked by the noncoding regions and terminal coding nucleotides from the A/WSN/33 influenza NA segment. The $3^{\prime}$ vRNA sequence contained three nucleotide differences and one nucleotide deletion relative to the flanking RBD in the pHW_NAflank_RBD_B7-1 construct. The sequence for pHH_NAflank_eGFP is available in the supplementary information (File S2).

Additional viral genes from A/WSN/33 were expressed from bidirectional reverse genetics plasmids [9], kindly provided by Robert Webster of St. Jude Children's Research Hospital. The H3 HA protein containing a Y98F mutation from A/Aichi/2/1968 was also cloned into the bidirectional pHW2000 backbone, and additional mutations G379W (Genbank sequence is in File S3) or R453G, were introduced into this construct to improve the rescue of neuraminidase-deficient viruses. The HA mutations are named in the canonical $\mathrm{H} 3$ ectodomain numbering scheme.

For cell surface expression studies, the protein sequence for the SARS-CoV-2 spike from (isolate Wuhan-1, Genbank NC_045512) was codon-optimized and contained a cytoplasmic tail truncation that removes the last 21 amino acids, as described previously [33]. Spike and the protein sequence for the membrane-anchored RBD in $\triangle \mathrm{NA}(\mathrm{RBD})$ were each cloned into an expression plasmid (HDM) which places the gene under the control of a cytomegalovirus (CMV) promoter, to generate plasmids HDM-SARS2-Spike-delta21 [33] and HDM_Spike_RBD_B7-1 (File S4).

\subsection{Generation of Viruses}

Influenza viruses were generated by reverse genetics, as previously described [34]. Briefly, we transfected a coculture of $293 \mathrm{~T}$ cells and MDCK-SIAT1-TMPRSS2 cells [34] with reverse genetics 
plasmids encoding the internal segments from the A/WSN/33 virus (PB1, PB2, PA, NP, M, NS), the hemagglutinin (HA) segment from the A/Aichi/2/1968 virus with an amino acid mutation in the receptor binding site (Y98F), and either the $\triangle \mathrm{NA}(\mathrm{RBD})$ or $\triangle \mathrm{NA}(\mathrm{GFP})$ segment described above, or the NA segment from the A/WSN/33 virus. Cells were plated at a density of $5 \times 10^{5} 293 \mathrm{~T}$ cells, and $0.5 \times 10^{5}$ MDCK-SIAT1-TMPRSS2 cells per well in a 6-well dish in D10 (Dulbecco modified Eagle medium supplemented with 10\% heat-inactivated fetal bovine serum (FBS), $2 \mathrm{mM}$ L-glutamine, $100 \mathrm{U}$ of penicillin/mL, and $100 \mu \mathrm{g}$ of streptomycin/mL). The next day, $200 \mathrm{ng}$ of each plasmid was transfected into the cells using the BioT transfection reagent (Bioland Sci, Paramount, CA, B01-02). Then, 12-18 h post-transfection (hpt), the medium was changed to influenza growth media (IGM; Opti-MEM supplemented with $0.01 \%$ heat-inactivated FBS, $0.3 \%$ bovine serum albumin (BSA), $100 \mathrm{U}$ of penicillin/mL, $100 \mu \mathrm{g}$ of streptomycin/mL, and $100 \mu \mathrm{g}$ of calcium chloride/mL). Viral supernatants were collected approximately $72 \mathrm{hpt}$ and the titer was determined by a fifty-percent tissue-culture infective dose (TCID50).

To generate inoculum for murine infections, viruses were expanded in low serum media. We infected MDCK-SIAT1-TMPRSS-2 cells at a low multiplicity of infection (MOI = 0.02 TCID50). The medium was changed to OptiMEM at $24 \mathrm{~h}$ postinfection (hpi) and the virus was collected $48-72 \mathrm{hpi}$. Viral supernatants were clarified to remove cells by filtering through a $0.45 \mu \mathrm{M}$ syringe filter, aliquoted, and stored at $-80{ }^{\circ} \mathrm{C}$. Viruses were titered by TCID50 prior to use in mouse experiments. The $\triangle \mathrm{NA}(\mathrm{RBD})$-Flu virus reached a titer of $1.7 \times 10^{4} \mathrm{TCID50/uL}$ following an expansion in OptiMEM. To verify that $\triangle N A(R B D)$ was stably maintained in NA segment, RNA was extracted from the viral supernatant with RNeasy kit (Qiagen, Germantown, MD, 74104), and reverse transcribed to produce cDNA (Agilent, Santa Clara, CA, 200820). The NA segment was amplified by PCR and visualized with a $1 \%$ agarose gel.

\subsection{Flow Cytometry}

293T cells were seeded at $6 \times 10^{5}$ cells/well in a 6-well plate, and cells were transfected twenty-four hours later with $500 \mathrm{ng}$ of either HDM-SARS-Spike-delta21 or HDM_Spike_RBD_B7-1 plasmids and $1.5 \mathrm{ng}$ of Transfection Carrier DNA (Promega, Madison, WI, E4881) using BioT reagent, according to manufacturer's protocol. Alternatively, the media was changed to IGM and cells were infected with either $\triangle \mathrm{NA}(\mathrm{RBD})$-Flu or $\triangle \mathrm{NA}(\mathrm{GFP})$-Flu. At $18 \mathrm{hpi} / \mathrm{hpt}$, the media was removed from cells, and cells were washed with phosphate buffered saline (PBS), dissociated from the plate with enzyme-free dissociation buffer (Thermo Fisher, Waltham, MA, 13151014), harvested by centrifugation at $1200 \times g$ for $3 \mathrm{~min}$, and washed in FACS buffer (PBS + 1\%, Bovine Serum Albumin). Cells were stained with either recombinant biotinylated ACE2 ectodomain (ACROBiosystems, Newark, DE, AC2-H82E6) or CR3022 antibody (kindly provided by Neil King and Mike Murphy, University of Washington, Institute for Protein Design) for $1 \mathrm{~h}$ at room temperature, washed with FACS buffer, resuspended in secondary stain, a 1:200 dilution of PE-conjugated streptavidin (Thermo Fisher, S866) or PE-conjugated Goat Anti-Human IgG (Jackson ImmunoResearch Labs, West Grove, PA, 109-115-098), and incubated on ice for $1 \mathrm{~h}$. Cells were then washed twice in FACS buffer. Cells infected with the replicative virus were fixed in 1\% paraformaldehyde in FACS buffer for $15 \mathrm{~min}$ on ice and washed twice more prior to FACS analysis. The RBD surface expression was assessed by measuring PE-positive cell populations with a BD FACSCanto II instrument. For each sample, 10,000 events were collected, and the data shown were gated to select singleton events. The analysis and compensation were performed using FlowJo v10.7. The histograms shown are for a single well of stained cells. However, the verification of the surface expression of RBD upon infection with $\triangle \mathrm{NA}(\mathrm{RBD})$-Flu was replicated on a separate day.

\subsection{Animal Studies}

Seven week old female BALB/cJ mice (Jackson Labs, Sacramento, CA) were anesthetized intraperitonially with $100 \mathrm{mg} / \mathrm{kg}$ of ketamine $+10 \mathrm{mg} / \mathrm{kg}$ of xylazine in PBS and infected intranasally with $50 \mathrm{uL}$ of either a high $\left(8 \times 10^{5} \mathrm{TCID} 50\right)$ or low $\left(8 \times 10^{4} \mathrm{TCID} 50\right)$ dose of $\triangle \mathrm{NA}(\mathrm{RBD})$-Flu, or with 
$\triangle \mathrm{NA}(\mathrm{GFP})$-Flu virus $\left(8 \times 10^{4}\right.$ TCID50), or mock infected with OptiMEM. Four animals were inoculated per condition. At 14 and 21 days postinfection, blood was collected from mice by a retro-orbital bleed and/or cardiac puncture at the terminal time point. The blood samples clotted at room temperature for 30-60 min and then were centrifuged at $1000 \times g$ for $10 \mathrm{~min}$ at $4{ }^{\circ} \mathrm{C}$ to separate the cellular debris and plasminogen from the sera. The sera were stored at $-80^{\circ} \mathrm{C}$ until use. Animal work was conducted according to protocol PROTO201900016 (1893), approved by Fred Hutchinson Cancer Research Center Institutional Animal Care and Use Committee (9 June 2020).

\subsection{Spike Pseudotyped Lentivirus Neutralization Assays}

SARS-CoV-2 spike-pseudotyped lentivirus neutralization assays were performed as previously described [33,35], with slight modifications. The spike protein of SARS-CoV-2 that was used to produce pseudotyped lentivirus contained a cytoplasmic tail truncation that removes the last 21 amino acids [33]. Infections of 293T-ACE2 cells were performed in poly-L-lysine coated plates. The sera were heat-inactivated for $30 \mathrm{~min}$ at $56^{\circ} \mathrm{C}$ immediately prior to use. Three-fold dilutions of sera were done starting at a 1:20 dilution. The serum was incubated with the virus for $1 \mathrm{~h}$ at this concentration (which was used to calculate IC50s) and then diluted 2:3 when transferred onto cells. The luciferase activity was measured at $65 \mathrm{hpi}$ following a transfer to opaque black-bottom plates. Samples were run in duplicate and each plate included no-serum and no-virus controls. The fraction infectivity was calculated by normalizing the luciferase reading for each sample by the average of two no-serum control wells in the same row. All neutralization curves show the mean and standard error of duplicate curves run on the same 96-well plate. The neutralization curves were plotted using the neutcurve Python package (https://jbloomlab.github.io/neutcurve/, 0.3.1), which fits a two-parameter Hill curve, with the top baseline fixed to one and the bottom baseline fixed to zero.

\subsection{Influenza Neutralization Assays}

Sera were treated with receptor-destroying enzyme (RDE) to ensure that the virus would not bind to residual sialic acids present in the serum. One vial of lyophilized RDE II (Denka Seiken, Tokyo, JP, 370013) was first resuspended in $20 \mathrm{~mL}$ PBS. We then incubated $10 \mu \mathrm{L}$ of serum with $30 \mu \mathrm{L}$ of RDE solution at $37^{\circ} \mathrm{C}$ for $3 \mathrm{~h}$, heat-inactivated the serum and RDE by incubating at $56^{\circ} \mathrm{C}$ for $30 \mathrm{~min}$, centrifuged the serum at $6000 \times g$ for $2 \mathrm{~min}$ to pellet any precipitated material and collected the supernatant. Neutralization was measured against the virus containing $\mathrm{H} 3$ from the A/Aichi/2/1968 virus with two mutations, Y98F and G379W, carrying GFP in the PB1 segment, and all other internal genes from A/WSN/33. The neutralization assays were performed in MDCK-SIAT1-CMV-PB1 cells using this GFP-expressing virus as described previously [36-39]. As with spike pseudotyped lentivirus neutralization assays, the curves were plotted and IC50s were calculated using the neutcurve Python package.

\section{Results}

\subsection{Engineering and Characterization of Influenza Virus Encoding SARS-CoV-2 RBD}

We set out to incorporate a membrane-anchored form of the receptor binding domain (RBD) of SARS-CoV-2 spike into the influenza genome. To enable the cell-surface display of the RBD protein, we appended a mammalian signal peptide to the $\mathrm{N}$-terminus of the RBD and a transmembrane region and cytoplasmic domain from murine B7.1 to the C-terminus of the RBD. The murine B7.1 sequence was used as it has previously been shown to induce high levels of surface expression of chimeric proteins [29]. We engineered the neuraminidase (NA) segment of the A/WSN/33 influenza virus to replace the NA coding sequence with a sequence encoding the membrane-anchored RBD and named the resulting construct $\triangle \mathrm{NA}(\mathrm{RBD})$ (Figure 1A). To facilitate the packaging of this segment into influenza virions, the packaging signals located at the NA segment termini, which the span coding and noncoding regions of vRNA, were retained (Figure 1A). These terminal packaging signals comprised 113 and $126 \mathrm{bp}$ at the $3^{\prime}$ and $5^{\prime}$ ends of the vRNA, respectively [30,31]. Mutations were introduced in 
these regions to remove the start codons upstream of the RBD coding sequence, as well as eliminate a cryptic bacterial promoter (see the plasmid map in File S1). Restriction sites were inserted immediately adjacent to the NA packaging signal on both the $5^{\prime}$ and the $3^{\prime}$ ends of the coding sequence.

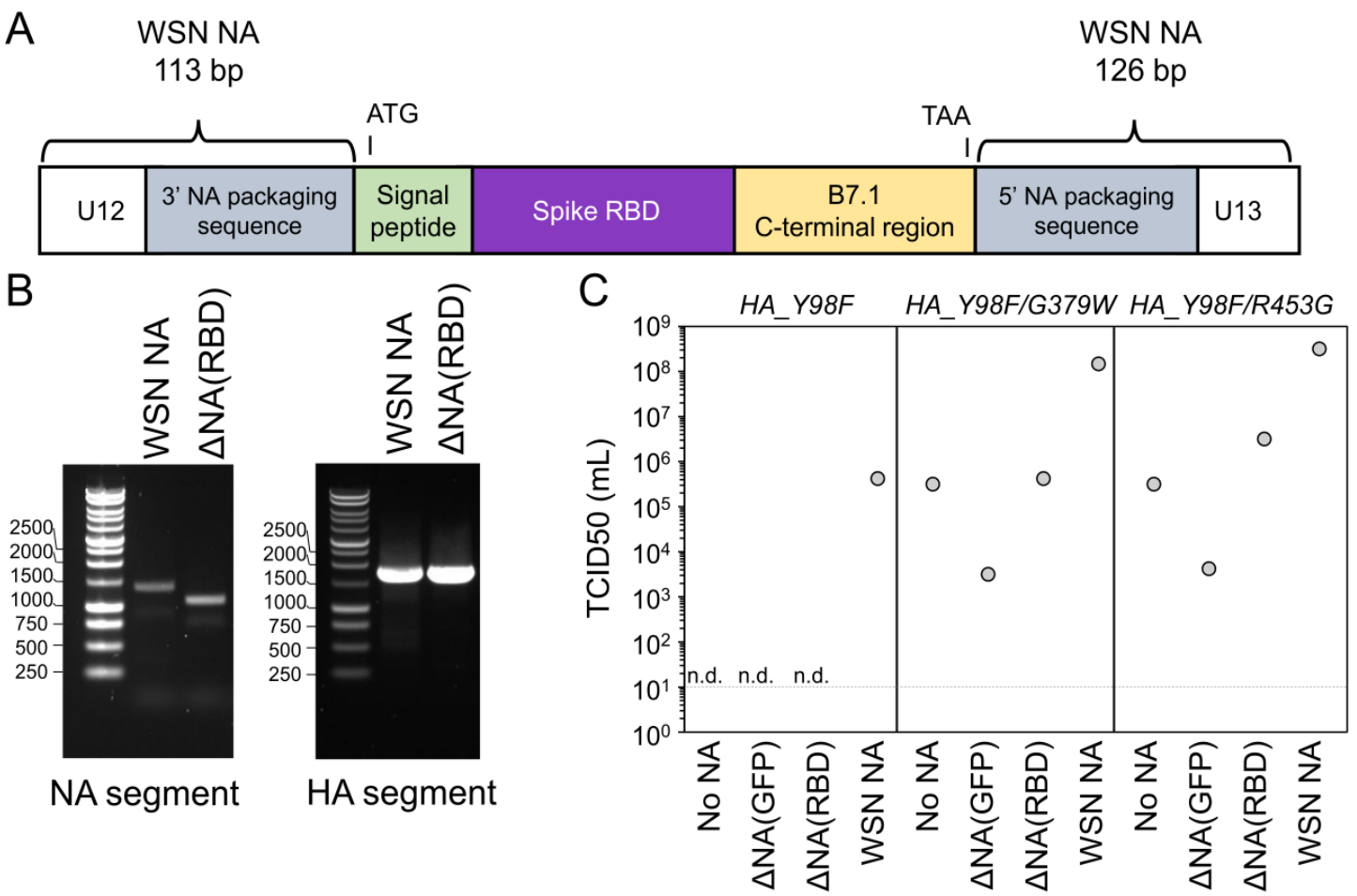

Figure 1. Design and characterization of a neuraminidase-deficient influenza virus containing receptor binding domain (RBD) of SARS-CoV-2 spike protein. (A) Schematic diagram of construct encoding SARS-CoV-2 Spike RBD with a eukaryotic signal peptide and the transmembrane region and cytoplasmic tail from murine B7.1 [29] in the neuraminidase (NA) segment of influenza virus. Sequence for RBD is flanked at the $5^{\prime}$ and $3^{\prime}$ ends by the noncoding and coding terminal packaging regions of the NA viral RNA (vRNA) segment from A/WSN/33. Start (ATG) and stop codons (TAA) are shown to indicate the region that is expressed in cells. Note that the schematic is drawn in the orientation of the positive-sense mRNA, not the negative sense vRNA. (B) Agarose gel of amplified NA and hemagglutinin (HA) segments from $\triangle \mathrm{NA}(\mathrm{RBD})$-Flu. For comparison, HA and NA segments from virus containing a wildtype NA segment are also shown. The expected sizes of bands are: wildtype $\mathrm{NA}=1409 \mathrm{bp}, \Delta \mathrm{NA}(\mathrm{RBD})=1125 \mathrm{bp}$, and HA $=1765 \mathrm{bp}$. (C) The effect of introducing G379W and R453G into H3_Y98F HA on viral titers. TCID50/mL is shown for reverse genetics for viruses with no NA segment, or the indicated NA segment. Values shown represent titers from a single reverse genetics experiment. Limit of detection is indicated with a horizontal dashed line. Samples where no cytopathic effect was observed are indicated with "n.d." (none detected).

We used reverse genetics to generate influenza virions encoding the $\triangle N A(R B D)$ segment and named the resulting virus $\triangle \mathrm{NA}(\mathrm{RBD})$-Flu. In addition to the $\triangle \mathrm{NA}(\mathrm{RBD})$ segment, these viruses contained the hemagglutinin (HA) segment from the A/Aichi/2/1968 (H3N2) strain with an amino acid mutation (Y98F) that reduces the affinity for HA's sialic acid receptor [40]. The Y98F mutation was included for two reasons: first, we anticipated that it would improve the growth of viruses that lacked an NA, which typically counterbalances HA's receptor-binding activity [36,40]; second, because viruses with this mutation are known to be severely attenuated in mice [4]. The remaining influenza genes of $\triangle \mathrm{NA}(\mathrm{RBD})$-Flu were derived from the mouse- and lab-adapted strain A/WSN/33 (H1N1). The viral supernatant from reverse genetics was blind passaged twice in MDCK-SIAT1-TMPRSS2 cells at three-day intervals. Upon the final passage, the cytopathic effect was evident in the well containing $\Delta \mathrm{NA}(\mathrm{RBD})-\mathrm{Flu}$, suggesting the presence of a replicating virus. 
Next, we verified that the RBD sequence was stably maintained in the NA segment. We extracted RNA from the viral supernatant from the final passage, and reverse transcribed and PCR-amplified the HA and NA segments (Figure 1B). The size of the NA segment isolated from $\triangle N A(R B D)$-Flu was consistent with the expected size of this segment. Sanger sequencing was performed on both the NA and HA segments to identify any potential tissue-culture adaptations. No mutations were identified in the $\triangle \mathrm{NA}(\mathrm{RBD})$ segment. However, a single amino acid substitution was present in HA (G379W), which we speculated might aid the growth of these engineered virions. We validated that this mutation, and an additional HA mutation isolated in a virus with no NA segment (R453G), improved the titers of $\triangle \mathrm{NA}(\mathrm{RBD})$-Flu generated by reverse genetics, although the titers were still lower than for a virus with the same HA and an intact NA segment (Figure 1C). The mechanism for how these mutations in HA2 might improve titers from reverse genetics is not known. For all subsequent experiments, the originally isolated and amplified $\triangle \mathrm{NA}(\mathrm{RBD})$-Flu, containing H3_Y98F/G379W, was used. As a control, we used a virus containing this HA (H3_Y98F/G379W) and GFP in the NA segment ( $\triangle \mathrm{NA}(\mathrm{GFP})$-Flu).

\subsection{Cells Infected with $\triangle N A(R B D)$-Flu Express High Levels of RBD on Their Surface}

We next set out to determine if cells transfected with the membrane-anchored RBD gene or infected with $\triangle \mathrm{NA}(\mathrm{RBD})$-Flu expressed RBD on their surface. To do this, we transfected cells with a mammalian protein expression plasmid encoding the membrane-anchored RBD or the SARS-CoV-2 spike (lacking the last 21 amino acids of the cytoplasmic tail). We also infected cells with either $\triangle N A(R B D)-F l u$ or $\triangle \mathrm{NA}(\mathrm{GFP})$-Flu. We stained the cells with a soluble recombinant version of ACE2, the host receptor that is bound by the SARS-CoV-2 spike's RBD to mediate viral entry. We separately stained the cells with the antibody CR3022, which binds to the RBD in a region which does not overlap with the ACE2 binding site [41,42]. There were high levels of RBD expression on the surface of transfected and infected cells labeled with both ACE2 and CR3022 (Figure 2). Notably, cells transfected with the membrane-anchored RBD had substantially higher staining of RBD on their surface than cells transfected with spike, and cells infected with $\triangle N A(R B D)$-Flu had even higher levels of RBD than the transfected cells (Figure 2).

\section{3. $\triangle N A(R B D)$-Flu Induces Neutralizing Antibodies Against SARS-CoV-2 and Influenza Virus Without Causing Disease in Mice}

To determine if the $\triangle \mathrm{NA}(\mathrm{RBD})$-Flu virus induces an anti-RBD antibody response in vivo, we intranasally infected four groups of four mice with either a high dose $\left(8 \times 10^{5} \mathrm{TCID50}\right)$ or lower dose of $\triangle \mathrm{NA}(\mathrm{RBD})$-Flu $\left(8 \times 10^{4} \mathrm{TCID} 50\right)$, a control virus expressing GFP in the NA segment ( $\triangle \mathrm{NA}(\mathrm{GFP})$-Flu, at $8 \times 10^{4}$ TCID50), or performed a mock infection (Figure 3A). Mice were monitored for seven days postinfection for signs of illness, including reduced activity, ruffled fur, hunched posture, and weight loss (Figure 3B). No signs of disease or weight loss were observed in any group (Figure 3B). 

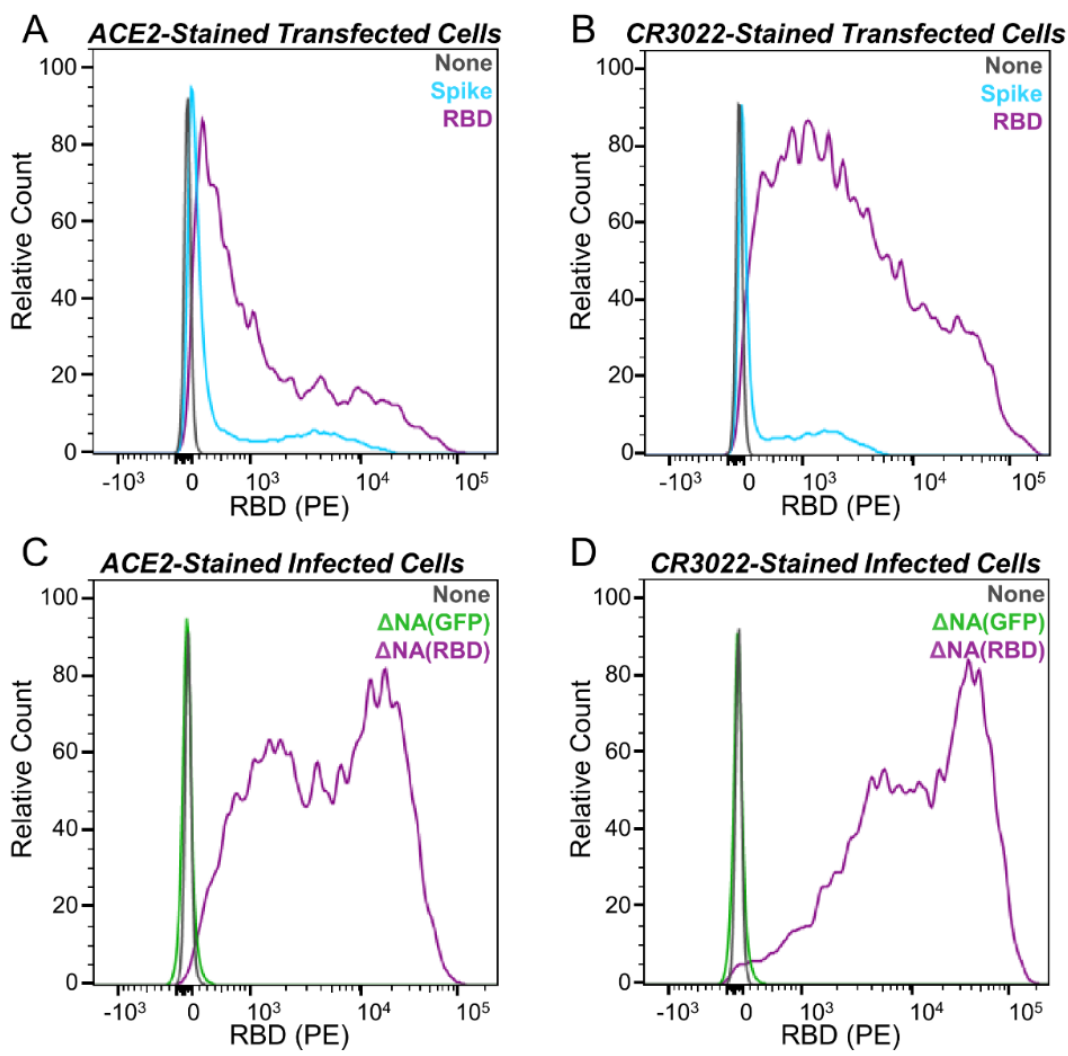

Figure 2. Infection with $\triangle \mathrm{NA}(\mathrm{RBD})$-Flu leads to expression of RBD on the surface of $293 \mathrm{~T}$ cells. Histograms, normalized to mode, of flow cytometry measurements showing RBD expression on the cell surface for: (A) Cells transfected with the mammalian expression plasmids HDM-SARS-Spike-delta21 or HDM_Spike_RBD_B7-1 and stained with ACE2 or (B) stained with CR3022 antibody, (C) Cells infected with $\triangle \mathrm{NA}(\mathrm{RBD})$-Flu or $\triangle \mathrm{NA}(\mathrm{GFP})$-Flu and stained with ACE2 or (D) CR3022 antibody. Data shown are from a single population of stained cells.

We collected sera from the mice at 14 and 21 days postinfection (dpi) and measured anti-SARS-CoV-2 titers using a spike-pseudotyped lentivirus neutralization assay [33,35]. Neutralizing responses against SARS-Cov-2 were detected in mice infected with the $\triangle \mathrm{NA}(\mathrm{RBD})$-Flu at both 14 and 21 dpi (Figure 3C, curves available in Figure S1). Three of the four mice in each dose group had neutralizing titers at $14 \mathrm{dpi}$, while all mice infected with $\triangle \mathrm{NA}(\mathrm{RBD})$-Flu show neutralizing titers by $21 \mathrm{dpi}$ (Figure 3C). The neutralizing titers were higher for mice inoculated with a larger dose of $\triangle \mathrm{NA}(\mathrm{RBD})$-Flu, although the difference was not statistically significant. As expected, no neutralizing antibodies against SARS-CoV-2 Spike were detected in either the mock or $\triangle \mathrm{NA}(\mathrm{GFP})$-Flu infected mice (Figure 3C). These data indicate that a single intranasal inoculation with $\triangle \mathrm{NA}(\mathrm{RBD})$-Flu induces a rapid production of neutralizing antibodies against SARS-CoV-2.

Finally, we tested if the mice had also mounted an immune response to influenza virus. We performed influenza virus neutralization assays with blood collected at $21 \mathrm{dpi}$, using an influenza virus with the $\mathrm{H} 3$ from $\mathrm{A} / \mathrm{Aichi} / 2 / 1968$ with Y98F and G379W mutations (the same mutations present in the HA $\triangle \mathrm{NA}(\mathrm{RBD})$-Flu). As expected, high levels of neutralizing antibodies against influenza virus were present in mice infected with either $\Delta \mathrm{NA}(\mathrm{RBD})$-Flu or $\triangle \mathrm{NA}(\mathrm{GFP})$-Flu (Figure 3D). 
A

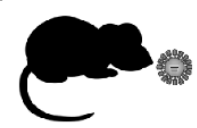

Day 0

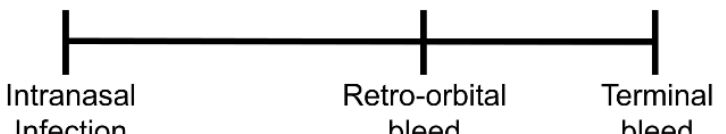

Infection

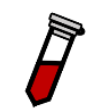

Day 14

C

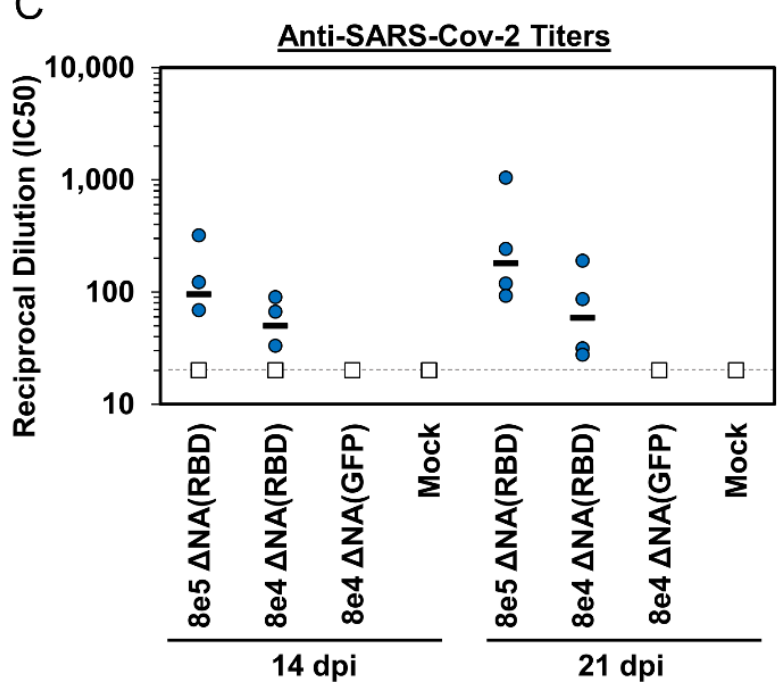

B

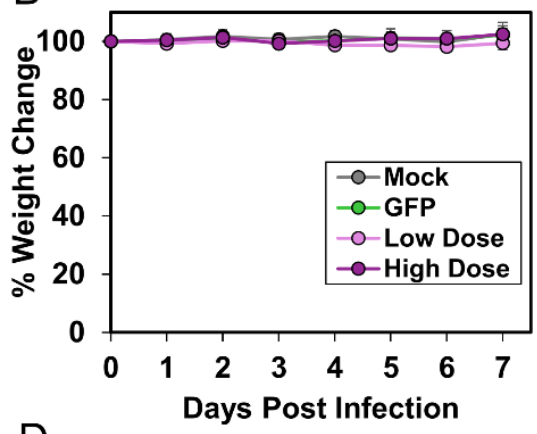

D

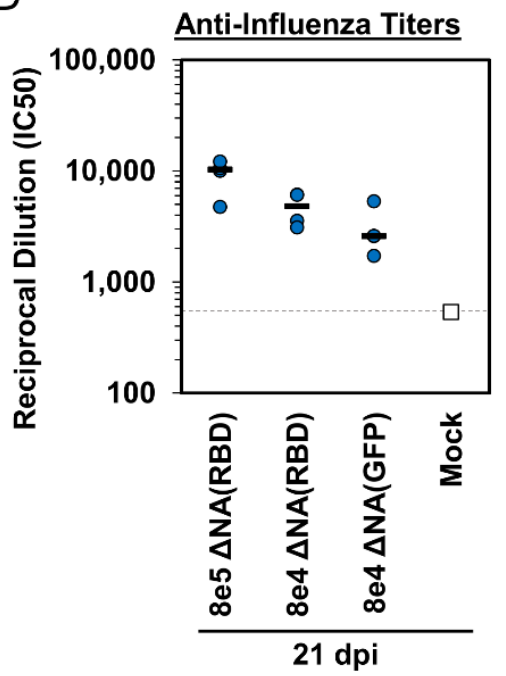

Figure 3. The $\triangle \mathrm{NA}(\mathrm{GFP})$-Flu virus induces neutralizing antibodies against influenza and SARS-CoV-2. (A) Schematic of timeline for intranasal infection and blood collection from mice. (B) Weight of individual mice was measured for the first seven days postintranasal infection to monitor disease severity for any signs of disease. Values shown are percent weight change from initial weight prior to infection on Day 0. Points are average and error bars are standard deviation of each group. Titers of neutralizing antibodies against (C) SARS-CoV-2 Spike-pseudotyped lentiviral particles at 14 and 21 days postinfection, and (D) influenza virus with the H3 HA from A/Aichi/2/1968 at 21 days postinfection. Y-axis values show reciprocal dilution of the fifty-percent inhibitory concentration (IC50). Blue circles denote titer from individual mice in each group, horizontal line indicates median titer for the group. Samples were run in duplicate. The dashed line indicates the limit of detection, points at that limit (white squares) are the lower bound. There are four mice in each group.

\section{Discussion}

Here we describe an engineered influenza virus, $\triangle N A(R B D)-F l u$, that expresses a membrane-anchored form of SARS-CoV-2 Spike RBD from its NA segment. The $\triangle N A(R B D)$-Flu virus stably maintains the gene encoding the RBD over multiple passages, and cells infected with this virus express high levels of RBD on their surface. An intranasal inoculation of mice with a single dose of $\triangle \mathrm{NA}(\mathrm{RBD})$-Flu elicits neutralizing antibodies against SARS-CoV-2 in mice, with titers comparable to those observed in humans following natural infection [33,43,44] or an administration of two doses of a mRNA-based vaccine in clinical trials [20]. Notably, the $\triangle N A(R B D)-F l u$ elicited these neutralizing antibody titers after just a single intranasal inoculation at a viral dose that is lower than that typically used for live-attenuated influenza vaccines $[4,13,45]$. It therefore seems possible that neutralizing antibody titers against SARS-CoV-2 could be further enhanced by using a higher viral dose in a single inoculation, and/or by boosting either with recombinant RBD or a second administration of a $\triangle \mathrm{NA}(\mathrm{RBD})$-Flu variant containing a different HA protein. 
Our study also has several important limitations. First, we examined the effect of $\Delta N A(R B D)$-Flu vaccination only in influenza-naïve mice. For other live attenuated vaccines, a pre-existing immunity against the vaccine vector (influenza virus, in this case) can reduce effectiveness [46,47]. This limitation could potentially be overcome by creating variants of $\triangle \mathrm{NA}(\mathrm{RBD})$-Flu that contain HA subtypes to which the human population is naïve, although we did not attempt that here. Second, we performed experiments using only a single strain of mice (BALB/cJ) and have not examined the results of vaccination with $\triangle \mathrm{NA}(\mathrm{RBD})$-Flu in nonhuman primates or other animal models. Third, although the $\triangle \mathrm{NA}(\mathrm{RBD})$-Flu grew to reasonably high titers that were sufficient for our experiments, the titers were still lower than those obtained using viruses with an intact NA segment. Fourth, although we demonstrated high SARS-CoV-2 neutralizing antibody titers at three weeks postvaccination, we did not perform experiments to examine the durability of these titers over longer timeframes. Finally, while the presence of neutralizing titers against SARS-CoV-2 is correlated with protection against infection in animal models [48,49] and preliminarily in human studies [50], we did not directly test if the neutralizing antibodies elicited by $\triangle \mathrm{NA}(\mathrm{RBD})$-Flu are protective against viral challenge.

Despite these limitations, vaccines based on $\triangle \mathrm{NA}(\mathrm{RBD})$-Flu have several possible advantages. First, the vaccine induces neutralizing antibodies with a just single dose. Second, live influenza viruses induce mucosal immune responses $[10,13,15,51]$ that may be important for protective immunity to SAR-CoV-2 [17,52]. Third, it might be possible to leverage additional influenza virus-engineering approaches such as those described in [11] to generate virions that express NA as well as RBD, and could serve as dual influenza- and SARS-CoV-2 vaccines. Finally, a major challenge to the rapid development and deployment of a vaccine for COVID-19 is scaling production in order to distribute a large number of doses worldwide. There is already existing infrastructure for the large-scale production of influenza virus-based vaccines which could in principle be extended to also produce live virus vaccines similar to $\triangle \mathrm{NA}(\mathrm{RBD})$-Flu at scale [23].

\section{Patents}

A.N.L., L.E.G., A.J.G., and J.D.B are listed as inventors on a provisional patent application based on the studies presented in this paper.

Supplementary Materials: The following are available online at http:/www.mdpi.com/1999-4915/12/9/987/s1, Figure S1: Neutralizing antibodies are present in mice at 14- and 21-days postinoculation with $\triangle N A(R B D)$-Flu, File S1: pHW_NAflank_RBD_B7-1(2788).gb, File S2: pHH_NAflank_eGFP(561).gb, File S3: pHW_X31_HA_Y98F _G379W(2786).gb, File S4: HDM_Spike_RBD_B7-1(2821).gb.

Author Contributions: Conceptualization, A.N.L. and J.D.B.; investigation, A.N.L., L.E.G., A.J.G., K.H.D.C., J.D.B.; writing—original draft preparation, A.N.L. and J.D.B.; writing—review and editing, all authors. All authors have read and agreed to the published version of the manuscript.

Funding: This research was supported by the following grants from the NIAID of the NIH: R01AI141707 and R01AI127893 (J.D.B.), F30AI149928 (to K.H.D.C.), and an NSF predoctoral fellowship to L.E.G. (DGE-1762114). J.D.B. is an Investigator of the Howard Hughes Medical Institute.

Acknowledgments: We thank Mike Murphy and Neil King for the generous contribution of CR3022 antibody. We also thank members of the Comparative Medicine staff at Fred Hutchinson Cancer Research Center (FHCRC) who assisted with animal experiments. We also thank members of the Flow Cytometry Core at FHCRC for assistance.

Conflicts of Interest: The authors declare no conflict of interest.

\section{References}

1. Li, Q.; Guan, X.; Wu, P.; Wang, X.; Zhou, L.; Tong, Y.; Ren, R.; Leung, K.S.M.; Lau, E.H.Y.; Wong, J.Y.; et al. Early transmission dynamics in Wuhan, China, of novel coronavirus-infected pneumonia. N. Engl. J. Med. 2020, 382, 1199-1207. [CrossRef]

2. World Health Organization. Coronavirus disease (COVID-19) Situation Report-183; World Health Organization: Geneva, Switzerland, 2020. 
3. Stokes, E.K.; Zambrano, L.D.; Anderson, K.N.; Marder, E.P.; Raz, K.M.; El Burai Felix, S.; Tie, Y.; Fullerton, K.E. Coronavirus Disease 2019 Case Surveillance-United States, 22 January-30 May 2020. MMWR. Morb. Mortal. Wkly. Rep. 2020, 69, 759-765. [CrossRef] [PubMed]

4. $\quad$ Meisner, J.; Szretter, K.J.; Bradley, K.C.; Langley, W.A.; Li, Z.-N.; Lee, B.-J.; Thoennes, S.; Martin, J.; Skehel, J.J.; Russell, R.J.; et al. Infectivity Studies of Influenza Virus Hemagglutinin Receptor Binding Site Mutants in Mice. J. Virol. 2008, 82, 5079-5083. [CrossRef] [PubMed]

5. Shinya, K.; Fujii, Y.; Ito, H.; Ito, T.; Kawaoka, Y. Characterization of a Neuraminidase-Deficient Influenza A Virus as a Potential Gene Delivery Vector and a Live Vaccine. J. Virol. 2004, 78, 3083-3088. [CrossRef] [PubMed]

6. Mishin, V.P.; Nedyalkova, M.S.; Hayden, F.G.; Gubareva, L.V. Protection afforded by intranasal immunization with the neuraminidase-lacking mutant of influenza A virus in a ferret model. Vaccine 2005, 23, 2922-2927. [CrossRef] [PubMed]

7. Smith, A.; Rodriguez, L.; El Ghouayel, M.; Nogales, A.; Chamberlain, J.M.; Sortino, K.; Reilly, E.; Feng, C.; Topham, D.J.; Martínez-Sobrido, L.; et al. A Live Attenuated Influenza Vaccine Elicits Enhanced Heterologous Protection When the Internal Genes of the Vaccine Are Matched to Those of the Challenge Virus. J. Virol. 2019, 94. [CrossRef]

8. Fujii, Y.; Goto, H.; Watanabe, T.; Yoshida, T.; Kawaoka, Y. Selective incorporation of influenza virus RNA segments into virions. Proc. Natl. Acad. Sci. USA 2003, 100, 2002-2007. [CrossRef]

9. Neumann, G.; Watanabe, T.; Ito, H.; Watanabe, S.; Goto, H.; Gao, P.; Hughes, M.; Perez, D.R.; Donis, R.; Hoffmann, E.; et al. Generation of influenza A viruses entirely from cloned cDNAs. Proc. Natl. Acad. Sci. USA 1999, 96, 9345-9350. [CrossRef]

10. Chen, Z.; Baz, M.; Lu, J.; Paskel, M.; Santos, C.; Subbarao, K.; Jin, H.; Matsuoka, Y. Development of a High-Yield Live Attenuated H7N9 Influenza Virus Vaccine That Provides Protection against Homologous and Heterologous H7 Wild-Type Viruses in Ferrets. J. Virol. 2014, 88, 7016-7023. [CrossRef]

11. Harding, A.T.; Heaton, B.E.; Dumm, R.E.; Heaton, N.S. Rationally designed influenza virus vaccines that are antigenically stable during growth in eggs. MBio 2017, 8. [CrossRef]

12. Breen, M.; Nogales, A.; Baker, S.F.; Martínez-Sobrido, L. Replication-competent influenza a viruses expressing reporter genes. Viruses 2016, 8, 179. [CrossRef] [PubMed]

13. Martina, B.E.E.; van den Doel, P.; Koraka, P.; van Amerongen, G.; Spohn, G.; Haagmans, B.L.; Provacia, L.B.V.; Osterhaus, A.D.M.E.; Rimmelzwaan, G.F. A Recombinant Influenza A Virus Expressing Domain III of West Nile Virus Induces Protective Immune Responses against Influenza and West Nile Virus. PLoS ONE 2011, 6, e18995. [CrossRef] [PubMed]

14. Li, Z.-N.; Mueller, S.N.; Ye, L.; Bu, Z.; Yang, C.; Ahmed, R.; Steinhauer, D.A. Chimeric Influenza Virus Hemagglutinin Proteins Containing Large Domains of the Bacillus anthracis Protective Antigen: Protein Characterization, Incorporation into Infectious Influenza Viruses, and Antigenicity. J. Virol. 2005, 79, 10003-10012. [CrossRef] [PubMed]

15. Muster, T.; Ferko, B.; Klima, A.; Purtscher, M.; Trkola, A.; Schulz, P.; Grassauer, A.; Engelhardt, O.G.; García-Sástre, A.; Palese, P. Mucosal model of immunization against human immunodeficiency virus type 1 with a chimeric influenza virus. J. Virol. 1995, 69, 6678-6686. [CrossRef]

16. Li, J.; Diaz-Arévalo, D.; Chen, Y.; Zeng, M. Intranasal Vaccination with an Engineered Influenza Virus Expressing the Receptor Binding Subdomain of Botulinum Neurotoxin Provides Protective Immunity Against Botulism and Influenza. Front. Immunol. 2015, 6, 170. [CrossRef]

17. Moreno-Fierros, L.; García-Silva, I.; Rosales-Mendoza, S. Development of SARS-CoV-2 vaccines: Should we focus on mucosal immunity? Expert Opin. Biol. Ther. 2020, 1-6. [CrossRef]

18. Ravichandran, S.; Coyle, E.M.; Klenow, L.; Tang, J.; Grubbs, G.; Liu, S.; Wang, T.; Golding, H.; Khurana, S. Antibody signature induced by SARS-CoV-2 spike protein immunogens in rabbits. Sci. Transl. Med. 2020, 12, eabc3539. [CrossRef]

19. He, Y.; Zhou, Y.; Liu, S.; Kou, Z.; Li, W.; Farzan, M.; Jiang, S. Receptor-binding domain of SARS-CoV spike protein induces highly potent neutralizing antibodies: Implication for developing subunit vaccine. Biochem. Biophys. Res. Commun. 2004, 324, 773-781. [CrossRef]

20. Mulligan, M.J.; Lyke, K.E.; Kitchin, N.; Absalon, J.; Gurtman, A.; Lockhart, S.; Neuzil, K.; Raabe, V.; Bailey, R.; Swanson, K.A.; et al. Phase 1/2 Study to Describe the Safety and Immunogenicity of a COVID-19 RNA Vaccine Candidate (BNT162b1) in Adults 18 to 55 Years of Age: Interim Report. medRxiv 2020. [CrossRef] 
21. Chen, W.-H.; Tao, X.; Peng, B.-H.; Pollet, J.; Strych, U.; Bottazzi, M.E.; Hotez, P.J.; Lustigman, S.; Du, L.; Jiang, S.; et al. Yeast-Expressed SARS-CoV Recombinant Receptor-Binding Domain (RBD219-N1) Formulated with Alum Induces Protective Immunity and Reduces Immune Enhancement. bioRxiv 2020. [CrossRef]

22. Mercado, N.B.; Zahn, R.; Wegmann, F.; Loos, C.; Chandrashekar, A.; Yu, J.; Liu, J.; Peter, L.; McMahan, K.; Tostanoski, L.H.; et al. Single-shot Ad26 vaccine protects against SARS-CoV-2 in rhesus macaques. Nature 2020, 1-11. [CrossRef] [PubMed]

23. Sun, W.; Leist, S.R.; McCroskery, S.; Liu, Y.; Slamanig, S.; Oliva, J.; Amanat, F.; Schäfer, A.; Dinnon III, K.H.; García-Sastre, A.; et al. Newcastle disease virus (NDV) expressing the spike protein of SARS-CoV-2 as vaccine candidate 1 2. bioRxiv 2020. [CrossRef]

24. Cao, Y.; Su, B.; Guo, X.; Sun, W.; Deng, Y.; Bao, L.; Zhu, Q.; Zhang, X.; Zheng, Y.; Geng, C.; et al. Potent Neutralizing Antibodies against SARS-CoV-2 Identified by High-Throughput Single-Cell Sequencing of Convalescent Patients' B Cells. Cell 2020, 182, 73-84.e16. [CrossRef] [PubMed]

25. Shi, R.; Shan, C.; Duan, X.; Chen, Z.; Liu, P.; Song, J.; Song, T.; Bi, X.; Han, C.; Wu, L.; et al. A human neutralizing antibody targets the receptor binding site of SARS-CoV-2. Nature 2020, 1-5. [CrossRef]

26. Walls, A.C.; Park, Y.J.; Tortorici, M.A.; Wall, A.; McGuire, A.T.; Veesler, D. Structure, Function, and Antigenicity of the SARS-CoV-2 Spike Glycoprotein. Cell 2020, 181, 281-292.e6. [CrossRef]

27. Pinto, D.; Park, Y.J.; Beltramello, M.; Walls, A.C.; Tortorici, M.A.; Bianchi, S.; Jaconi, S.; Culap, K.; Zatta, F.; De Marco, A.; et al. Cross-neutralization of SARS-CoV-2 by a human monoclonal SARS-CoV antibody. Nature 2020, 583, 290-295. [CrossRef]

28. Starr, T.N.; Greaney, A.J.; Hilton, S.K.; Ellis, D.; Crawford, K.H.D.; Dingens, A.S.; Navarro, M.J.; Bowen, J.E.; Tortorici, M.A.; Walls, A.C.; et al. Deep mutational scanning of SARS-CoV-2 receptor binding domain reveals constraints on folding and ACE2 binding. Cell 2020. [CrossRef]

29. Lin, Y.C.; Chen, B.M.; Lu, W.C.; Su, C.I.; Prijovich, Z.M.; Chung, W.C.; Wu, P.Y.; Chen, K.C.; Lee, I.C.; Juan, T.Y.; et al. The B7-1 Cytoplasmic Tail Enhances Intracellular Transport and Mammalian Cell Surface Display of Chimeric Proteins in the Absence of a Linear ER Export Motif. PLoS ONE 2013, 8, e75084. [CrossRef]

30. Gao, Q.; Palese, P. Rewiring the RNAs of influenza virus to prevent reassortment. Proc. Natl. Acad. Sci. USA 2009, 106, 15891-15896. [CrossRef]

31. Rimmelzwaan, G.F.; Nieuwkoop, N.J.; de Mutsert, G.; Boon, A.C.M.; Kuiken, T.; Fouchier, R.A.M.; Osterhaus, A.D.M.E. Attachment of infectious influenza A viruses of various subtypes to live mammalian and avian cells as measured by flow cytometry. Virus Res. 2007, 129, 175-181. [CrossRef]

32. Hoffmann, E.; Neumann, G.; Kawaoka, Y.; Hobom, G.; Webster, R.G. A DNA transfection system for generation of influenza A virus from eight plasmids. Proc. Natl. Acad. Sci. USA 2000, 97, 6108-6113. [CrossRef] [PubMed]

33. Crawford, K.H.D.; Dingens, A.S.; Eguia, R.; Wolf, C.R.; Wilcox, N.; Logue, J.K.; Shuey, K.; Casto, A.M.; Fiala, B.; Wrenn, S.; et al. Dynamics of neutralizing antibody titers in the months after SARS-CoV-2 infection. medRxiv 2020, 1-15. [CrossRef]

34. Lee, J.M.; Huddleston, J.; Doud, M.B.; Hooper, K.A.; Wu, N.C.; Bedford, T.; Bloom, J.D. Deep mutational scanning of hemagglutinin helps predict evolutionary fates of human H3N2 influenza variants. Proc. Natl. Acad. Sci. USA 2018, 115, E8276-E8285. [CrossRef] [PubMed]

35. Crawford, K.H.D.; Eguia, R.; Dingens, A.S.; Loes, A.N.; Malone, K.D.; Wolf, C.R.; Chu, H.Y.; Tortorici, M.A.; Veesler, D.; Murphy, M.; et al. Protocol and Reagents for Pseudotyping Lentiviral Particles with SARS-CoV-2 Spike Protein for Neutralization Assays. Viruses 2020, 12, 513. [CrossRef] [PubMed]

36. Hooper, K.A.; Bloom, J.D. A Mutant Influenza Virus That Uses an N1 Neuraminidase as the Receptor-Binding Protein. J. Virol. 2013, 87, 12531-12540. [CrossRef] [PubMed]

37. Doud, M.B.; Lee, J.M.; Bloom, J.D. How single mutations affect viral escape from broad and narrow antibodies to H1 influenza hemagglutinin. Nat. Commun. 2018, 9, 1386. [CrossRef] [PubMed]

38. Lee, J.M.; Eguia, R.; Zost, S.J.; Choudhary, S.; Wilson, P.C.; Bedford, T.; Stevens-Ayers, T.; Boeckh, M.; Hurt, A.C.; Lakdawala, S.S.; et al. Mapping person-to-person variation in viral mutations that escape polyclonal serum targeting influenza hemagglutinin. Elife 2019, 8, e49324. [CrossRef]

39. Gentles, L.E.; Wan, H.; Eichelberger, M.C.; Bloom, J.D. Antibody Neutralization of an Influenza Virus that Uses Neuraminidase for Receptor Binding. Viruses 2020, 12, 597. [CrossRef] 
40. Martín, J.; Wharton, S.A.; Lin, Y.P.; Takemoto, D.K.; Skehel, J.J.; Wiley, D.C.; Steinhauer, D.A. Studies of the Binding Properties of Influenza Hemagglutinin Receptor-Site Mutants. Virology 1998, 241, 101-111. [CrossRef]

41. Yuan, M.; Wu, N.C.; Zhu, X.; Lee, C.C.D.; So, R.T.Y.; Lv, H.; Mok, C.K.P.; Wilson, I.A. A highly conserved cryptic epitope in the receptor binding domains of SARS-CoV-2 and SARS-CoV. Science (80-) 2020, 368, 630-633. [CrossRef]

42. Tian, X.; Li, C.; Huang, A.; Xia, S.; Lu, S.; Shi, Z.; Lu, L.; Jiang, S.; Yang, Z.; Wu, Y.; et al. Potent binding of 2019 novel coronavirus spike protein by a SARS coronavirus-specific human monoclonal antibody. Emerg. Microbes Infect. 2020, 9, 382-385. [CrossRef] [PubMed]

43. Wu, F.; Wang, A.; Liu, M.; Wang, Q.; Chen, J.; Xia, S.; Ling, Y.; Zhang, Y.; Xun, J.; Lu, L.; et al. Neutralizing Antibody Responses to SARS-CoV-2 in a COVID-19 Recovered Patient Cohort and Their Implications. SSRN Electron. J. 2020. [CrossRef]

44. Suthar, M.S.; Zimmerman, M.G.; Kauffman, R.C.; Mantus, G.; Linderman, S.L.; Hudson, W.H.; Vanderheiden, A.; Nyhoff, L.; Davis, C.W.; Adekunle, O.; et al. Rapid Generation of Neutralizing Antibody Responses in COVID-19 Patients. Cell Reports Med. 2020, 1, 100040. [CrossRef]

45. Wang, L.; Liu, S.Y.; Chen, H.W.; Xu, J.; Chapon, M.; Zhang, T.; Zhou, F.; Wang, Y.E.; Quanquin, N.; Wang, G.; et al. Generation of a Live Attenuated Influenza Vaccine that Elicits Broad Protection in Mice and Ferrets. Cell Host Microbe 2017, 21, 334-343. [CrossRef]

46. Mohn, K.G.I.; Bredholt, G.; Brokstad, K.A.; Pathirana, R.D.; Aarstad, H.J.; Tøndel, C.; Cox, R.J. Longevity of B-cell and T-cell responses after live attenuated influenza vaccination in children. J. Infect. Dis. 2015, 211, 1541-1549. [CrossRef]

47. Mohn, K.G.I.; Zhou, F.; Brokstad, K.A.; Sridhar, S.; Cox, R.J. Boosting of Cross-Reactive and Protection-Associated T Cells in Children after Live Attenuated Influenza Vaccination. J. Infect. Dis. 2017, 215, 1527-1535. [CrossRef]

48. Yang, J.; Wang, W.; Chen, Z.; Lu, S.; Yang, F.; Bi, Z.; Bao, L.; Mo, F.; Li, X.; Huang, Y.; et al. A vaccine targeting the RBD of the $S$ protein of SARS-CoV-2 induces protective immunity. Nature 2020, 1-9. [CrossRef] [PubMed]

49. Imai, M.; Iwatsuki-Horimoto, K.; Hatta, M.; Loeber, S.; Halfmann, P.J.; Nakajima, N.; Watanabe, T.; Ujie, M.; Takahashi, K.; Ito, M.; et al. Syrian hamsters as a small animal model for SARS-CoV-2 infection and countermeasure development. Proc. Natl. Acad. Sci. USA 2020, 117, 16587-16595. [CrossRef]

50. Addetia, A.; Crawford, K.H.D.; Dingens, A.; Zhu, H.; Roychoudhury, P.; Huang, M.-L.; Jerome, K.R.; Bloom, J.D.; Greninger, A.L. Neutralizing antibodies correlate with protection from SARS-CoV-2 in humans during a fishery vessel outbreak with high attack rate. J. Clin. Microbiol. 2020. [CrossRef] [PubMed]

51. Blazevic, V.; Mac Trubey, C.; Shearer, G.M. Comparison of in vitro immunostimulatory potential of live and inactivated influenza viruses. Hum. Immunol. 2000, 61, 845-849. [CrossRef]

52. Grifoni, A.; Weiskopf, D.; Ramirez, S.I.; Smith, D.M.; Crotty, S.; Sette, A. Targets of T Cell Responses to SARS-CoV-2 Coronavirus in Humans with COVID-19 Disease and Unexposed Individuals. Cell 2020. [CrossRef] [PubMed]

(C) 2020 by the authors. Licensee MDPI, Basel, Switzerland. This article is an open access article distributed under the terms and conditions of the Creative Commons Attribution (CC BY) license (http://creativecommons.org/licenses/by/4.0/). 